\title{
Effects of seat surface inclination on respiration and speech production in children with spastic cerebral palsy
}

Hwa-Kyung Shin ${ }^{1}$, Eun-Jin Byeon ${ }^{1}$ and Seok Hun Kim² ${ }^{2 *}$

\begin{abstract}
Background: Respiratory and speech problems are commonly observed in children with cerebral palsy (CP). The purpose of this study was to identify if inclination of seat surface could influence respiratory ability and speech production in children with spastic diplegic CP.

Methods: Sixteen children with spastic diplegic CP, ages 6 to 12 years old, participated in this study. The subjects' respiratory ability (forced vital capacity (FVC), forced expiratory volume in $1 \mathrm{~s}$ (FEV1), peak expiratory flow (PEF), and maximum phonation time (MPT)) were measured in three sitting conditions: a seat surface inclined $0^{\circ}$, anterior $15^{\circ}$, and posterior $15^{\circ}$.

Results: FVC was significantly different across three inclinations of seat surface, $F(2,45)=3.81, P=0.03$. In particular, the subjects' FVC at a seat surface inclined anterior $15^{\circ}$ was significantly greater than at a seat surface inclined posterior $15^{\circ}(P<0.05)$. However, FEV1, PEF, and MPT were not significantly affected by seat surface inclination $(P>0.05)$.

Conclusions: The results suggest that anterior inclination of seat surface may provide a positive effect on respiratory function in children with spastic diplegic CP.
\end{abstract}

Keywords: Cerebral palsy, Ergonomics, Respiration, Seat inclination, Speech production

\section{Background}

Children with spastic cerebral palsy (CP) account for about $80 \%$ of all children with CP. They frequently show abnormal muscle tone, impaired muscle contraction, and altered postural control [1]. These abnormal muscle tones and movements not only adversely affect development of the trunk muscles that are the foundation of respiration, but also cause thoracic deformity, which leads to respiratory problems [2].

Approximately $40 \%$ of children with spastic CP experience the impairments of respiratory function [3]. The level of respiratory impairment is significantly greater in children with spastic diplegic CP than in those with spastic Hemiplegic CP [4]. Various therapeutic approaches have been introduced to improve respiratory functions in children with $\mathrm{CP}$, such as strengthening respiratory muscles

\footnotetext{
* Correspondence: skim@health.usf.edu

${ }^{2}$ School of Physical Therapy \& Rehabilitation Sciences, University of South Florida, 12901 Bruce B. Downs Blvd., MDC 77, Tampa, FL 33612, USA Full list of author information is available at the end of the article
}

[5], inhibiting muscle tone [5], swimming [6], treadmill walking [7], and cycle ergometer training [8].

An ergonomic approach that adjusts the orientation of sitting to support physical function has been studied in children with CP [9-13]. Evidence shows that the orientation of sitting position influences functions in children with CP [14], especially those who depend on a wheelchair for most of their daily activities [15]. The anterior-inclined seat may provide a positive effect to the function of the upper limbs [15] and postural control [14,16]. Studies have also reported that the inclination of sitting position affects the respiratory function and speech in children with $\mathrm{CP}$ $[12,17]$. Nevertheless, the effectiveness of the sitting position on these functions is inconclusive $[14,18]$. Thus, the purpose of this study was to investigate whether an ergonomic approach using three levels of seat inclination could affect respiratory patterns and maximum phonation in children with spastic diplegic CP. 


\section{Methods \\ Subjects}

Sixteen children with spastic diplegic CP were recruited from the Gumi area in Korea for this study (Table 1). Inclusion criteria were as follows: children who have a) an ability to maintain a sitting position independently, b) the Gross Motor Function Classification System (GMFCS) levels I to IV [19], and c) an ability to follow the examiner's instruction. Subjects who had a) any neurological disorder other than cerebral palsy and b) any orthopedic problem that limits the sitting balance were excluded from this study. This study was conducted in compliance with the ethical standards of the Declaration of Helsinki, and a parent or guardian of each child signed a written informed consent form prior to the experiment.

\section{Experimental procedures and equipment}

All experiments were performed at a local rehabilitation center. Each subject participated in one study session that took approximately $1 \mathrm{~h}$ to complete. The subjects were closely guarded by a physical therapist throughout the experiment.

\section{Sitting positions on the inclination chair}

The chair used in this study was an adjustable benchstyle chair without a backrest. The subjects were asked to sit on the chair with its seat surface inclined anterior $15^{\circ}$, horizontal $\left(0^{\circ}\right)$, and posterior $15^{\circ}$ [20] (Figure 1), and the order of sitting conditions was randomly selected for assessments of respiratory function and maximum phonation time. At each sitting, their feet touched the floor maintaining $90^{\circ}$ of their knee joint angle, and when needed, a foothold or a footrest was used to secure their feet to the floor [21] (Figure 1C). For each sitting position, the subjects were given a 5 -min adaptation period to get used to the change so that their respiration would be regular prior to the first testing trial. If needed, the subjects' parents or physical therapists provided them with minimal assistance to maintain their postures.

Table 1 Clinical characteristics of the children with cerebral palsy

\begin{tabular}{lll}
\hline Variables & Mean $\pm \mathbf{S D}^{\mathbf{a}}$ & Range \\
\hline Gender (M/F) & $8 / 8$ & \\
Age (year) & $10.06 \pm 1.98$ & $6 \sim 12$ \\
Height $(\mathrm{cm})$ & $127.31 \pm 8.97$ & $105 \sim 139$ \\
Weight $(\mathrm{kg})$ & $28.36 \pm 6.44$ & $18 \sim 42$ \\
GMFCS level & $2.44 \pm 1.21$ & $\mathrm{I} \sim \mathrm{IV}$ \\
\hline
\end{tabular}

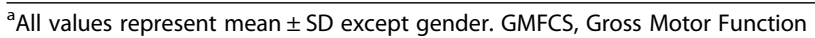
Classification System.

\section{Measurement of respiratory function}

The Cardio Touch 3000S (Bionet Co., Seoul, Korea) was used to measure respiratory function including forced vital capacity (FVC), forced expiratory volume in $1 \mathrm{~s}$ (FEV1), and peak expiratory flow (PEF). Subjects wore comfortable pants to minimize abdominal compression which might interfere with their respiratory activities during the assessments. FVC was determined by measuring the amount of a quick and strong expiration after a maximal inspiration. FEV1 was defined as the expiration amount of air for $1 \mathrm{~s}$ following a maximal inspiration, and PEF was determined by calculating the speed of the air emitted maximally. To ensure the subjects' understanding of the experiment, appropriate instructions and demonstrations were provided prior to the assessments. Each subject's nose was blocked to prevent air leakage. The subjects had a total of three trials with at least 3-min rest between trials, and the maximum value was used for further analysis.

\section{Measurement of speech production}

To assess speech production, the maximum phonation time (MPT) was determined using a stopwatch to measure the duration of the pronunciation of a vowel sound ('ah'). To enhance the credibility of the result, a speech therapist recorded and evaluated the phonation. The subjects performed a total of three trials for each randomly selected sitting position (seat surface inclined anterior $15^{\circ}, 0^{\circ}$, or posterior $15^{\circ}$ ) at their most comfortable pitch and strength, and the maximum value was used for further analysis.

\section{Statistical analysis}

One-way ANOVA was used to assess differences in FVC, FEV1, PEF, and MPT among three inclinations of seat surface using the IBM SPSS Statistics Software 22.0 (IBM Co., Armonk, NY, USA). Significance level was set at $P<0.05$ for each variable. When a significant difference was found, a post hoc analysis using Turkey tests was conducted to determine where the difference existed.

\section{Results}

\section{Respiration}

FVC was significantly different across three seat inclination positions, $F(2,45)=3.81, P=0.03$. Post hoc analysis indicated that $\mathrm{FVC}$ at anterior $15^{\circ}$ inclination of seat surface $(1.41 \pm 0.38 \mathrm{~L})$ was significantly greater than at posterior $15^{\circ}$ inclination of seat surface $(1.38 \pm 0.38 \mathrm{~L})$ $(P<0.05$, Figure 2$)$, but not significantly different from that of horizontal inclination $(1.09 \pm 0.34 \mathrm{~L})(P>0.05)$. No significant differences were found in FEV1, $F(2,45)=2.34$, $P=0.11$, and PEF, $F(2,45)=1.27, P=0.21$ across the three seat surface inclinations. Nonetheless, FEV1 and PEF at anterior $15^{\circ}(1.25 \pm 0.32 \mathrm{~L}$ and $2.11 \pm 0.88 \mathrm{~L} / \mathrm{s}$, 


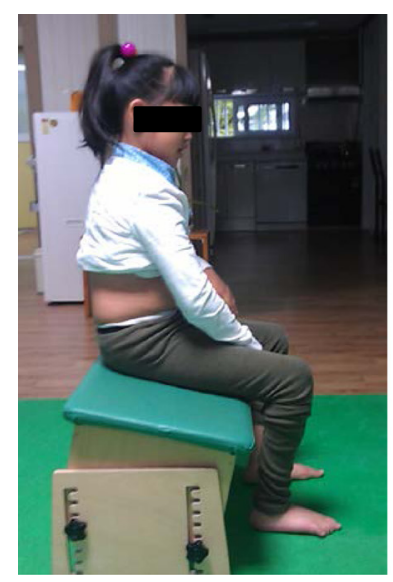

A. Anterior $15^{\circ}$ inclination



B. Horizontal

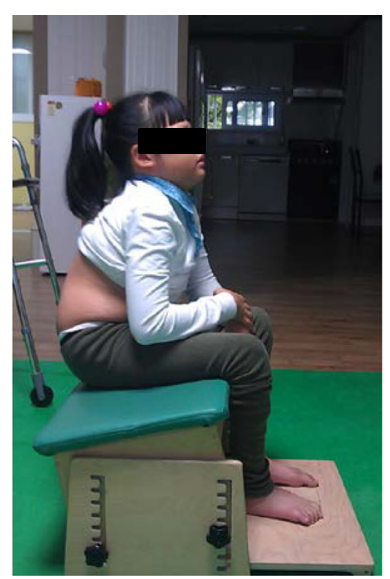

C. Posterior $15^{\circ}$ inclination

Figure 1 Three positions of seat surface inclination. Subjects' respiratory function and speech production were assessed in three seat inclination conditions: (A) $15^{\circ}$ of anterior inclination, (B) $0^{\circ}$ (horizontal) of inclination, and (C) $15^{\circ}$ of posterior inclination.

respectively) and horizontal inclinations $(1.24 \pm 0.32 \mathrm{~L}$ and $2.13 \pm 0.73 \mathrm{~L} / \mathrm{s}$, respectively) tended to be greater than those at posterior $15^{\circ}$ inclination $(1.02 \pm 0.37 \mathrm{~L}$ and $1.82 \pm 0.79 \mathrm{~L} / \mathrm{s}$, respectively).

\section{Speech production}

MPT of pronunciation of a vowel sound ('ah') was greater at a seat surface inclined anterior $15^{\circ}(6.91 \pm 2.09 \mathrm{~s})$ than when inclined $0^{\circ}(6.73 \pm 1.81 \mathrm{~s})$ and posterior $15^{\circ}(5.45 \pm$ $1.83 \mathrm{~s})$. However, no significant difference was found in MPT across the three seat surface inclinations, $F(2,45)=$ $2.80, P=0.07$ (Figure 3).

\section{Discussion}

Children with $\mathrm{CP}$ experience various pulmonary problems [22]. In particular, respiratory function is markedly diminished in children with spastic diplegic $\mathrm{CP}$, which may be due to the inefficient functions of respiratory muscles [4]. Altered breathing patterns, such as unsynchronized movements between the diaphragm and respiratory muscles, may result in shallow and rapid respiration in children with spastic CP [23]. Impairments in postural control may also contribute to abnormal respiratory function in children with spastic CP [20]. Studies have shown that the vital capacity varies depending on posture (for example, sitting position at various seat inclinations) [20] and this variation was significant in children with spastic diplegic CP [24].

An ergonomic approach has been recognized as a simple intervention to improve respiratory function in children with CP. A sitting device such as a wheelchair can be modified according to individual needs by inserting a frame and attaching a foothold or a backrest $[16,25]$. The modification of sitting posture changes the structure of respiratory muscles in resting position. Change in sitting posture can enhance the respiratory muscle activities, reduce the risk of airway blockage, and ultimately improve respiratory functions $[25,26]$. The chair-inclination intervention is an ergonomic approach that can affect posture and also can change function of the respiratory system. Respiration and speech production in healthy adults are affected by the chair tilt that helps maintain the neutral posture of the head and the trunk and promotes stable activities of the respiratory muscles $[27,28]$. In children with $\mathrm{CP}$, an appropriate hip joint angle is important for stable and balanced sitting, and the chair surface, which is used as a means of adjusting the hip joint angle, affects the change in spatial adjustment and therefore safety for the user [14-16,20].

A decrease in FVC is a major indicator of impaired respiratory function in children with spastic diplegic CP [4]. This present study shows that the FVC of children with spastic diplegic CP was greater with $15^{\circ}$ of anterior seat inclination than with $15^{\circ}$ of posterior seat inclination. The result suggests that sitting in an anterior-inclined seat may help children with $\mathrm{CP}$ maintain or improve their respiratory function. Children with spastic CP, because of their abnormal muscle tone and unstable posture, often display a particular way of sitting. To compensate for their unstable posture, their sitting position involves upper trunk flexion and posterior pelvic tilt [26]. Studies demonstrated that the anterior seat inclination helped the trunk extend into a more upright position $[29,30]$. The adapted sitting posture may allow the inspiratory and expiratory muscles to function more efficiently (for example, increased FVC). Whereas, the posterior seat inclination may increase both upper trunk flexion and posterior pelvic tilt, thereby adversely affecting the respiratory function.

Our study did not show a significant difference in either FEV1 or PEF over the three sitting positions, although the variables at anterior $15^{\circ}$ and horizontal inclinations were 


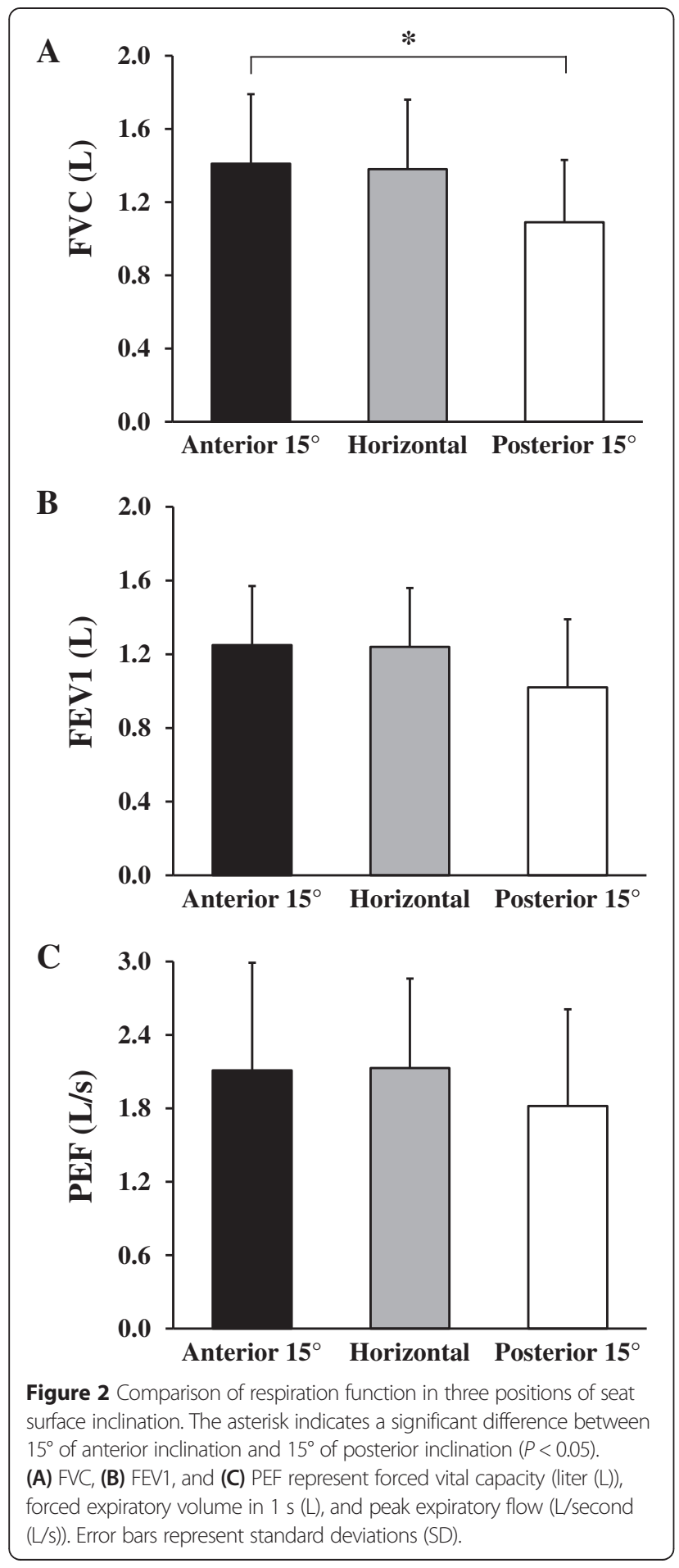

notably greater than those at posterior $15^{\circ}$ inclination. The result may be because FEV1 and PEF are not sensitive enough to identify the changes in respiratory function across the three seat inclinations. Moreover, the differences of respiratory measures were minimal between the anterior $15^{\circ}$ and horizontal inclinations, which were consistent with a previous study [31]. A long-term intervention study may

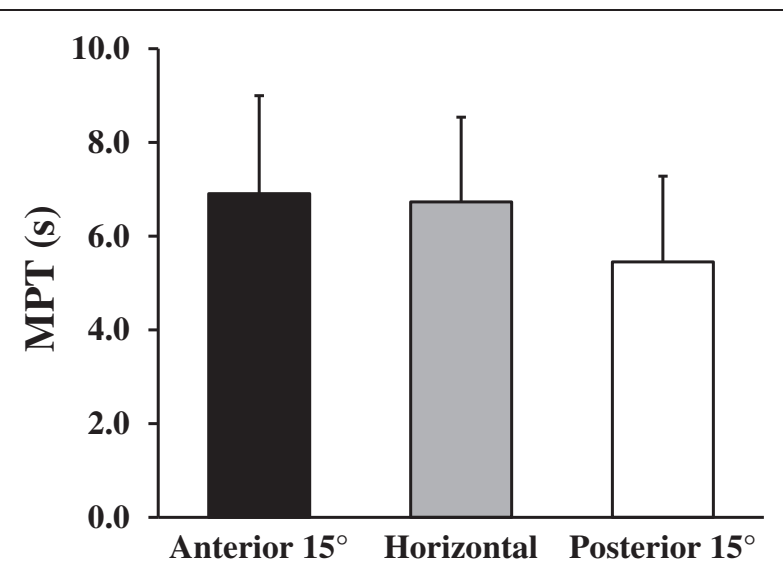

Figure $\mathbf{3}$ Comparison of maximum phonation time for speech production in three positions of seat surface inclination. MPT represents maximum phonation time (s). Error bars represent SD.

provide better insight into the effects of anterior seat inclination on respiratory function in children with CP. In addition, sitting on an anterior-inclined seat for extended periods of time may cause potential problems, such as excessive lumbar lordosis or lower back pain. Thus, this intervention approach should be combined with periodic assessment of sitting posture.

The MPT is often used to evaluate respiration and speech production [32]. In this study, no significant difference was observed in MPT across the three seat inclination positions. However, the results showed that children with spastic diplegic $\mathrm{CP}$ sitting at $15^{\circ}$ of anterior inclination had a slightly longer MPT than sitting at the horizontal or $15^{\circ}$ of posterior inclination position. The abnormal respiratory development may cause altered antagonistic functions of the abdominal and thoracic muscles during the expiration period. As a result, expiration is shortened, and the air flow required for speech is insufficiently formed, temporarily pausing respiration and speech production, and making it difficult to adjust loudness and pitch of the voice [33]. This respiratory pattern may affect phonation in children with spastic $\mathrm{CP}$ possibly because the deterioration of the abdominal muscle decreases the expiration volume and therefore phonation capacity [27]. Expiratory muscle strengthening exercise may be effective in achieving stable respiratory cycles and expiration volumes in order to eventually improve phonation [34].

Respiration is closely associated with several facets of speech sounds. The quality, duration, loudness, and pitch of phonation are greatly influenced by the condition of respiratory function. A study in people with multiple sclerosis suggested that to enhance the phonation quality, respiratory training approaches such as expiratory muscle strengthening exercise need to be combined with speech therapy [34]. Therefore, the seat-inclination 
intervention in daily activities or during speech therapy may accelerate positive results.

A limitation of this study was that the subjects fell within a wide range (from levels I to IV) of the GMFCS level and this may limit positive outcomes. Thus, the effect of a seat inclination approach on respiratory function and speech production in children with different levels of GMFCS needs to be addressed in future studies. It is also possible that ergonomic approaches tested in various environments and including postures other than sitting may provide children with spastic diplegic $\mathrm{CP}$ with more effective methods of respiratory function.

\section{Conclusions}

In this study, the FVC, FEV1, PEF, and MPT were assessed to determine the optimal chair inclination for effective respiration and speech production of children with spastic diplegic CP. A significant difference was observed in the FVC across three seat inclination conditions. The FVC was significantly enhanced with the anterior seat inclination compared to the posterior seat inclination. These results suggest that adjustment of seat inclination may be an effective intervention to improve the respiratory function of children with spastic diplegic CP.

\section{Abbreviations}

ANOVA: analysis of variance; CP: cerebral palsy; FEV1: forced expiratory volume in $1 \mathrm{~s}$; FVC: forced vital capacity; GMFCS: Gross Motor Function Classification System; L: Liter; L/s: liter/second; M/F: male/female; MPT: maximum phonation time; PEF: peak expiratory flow; SPSS: Statistical Package for the Social Sciences.

\section{Competing interests}

The authors declare that they have no competing interests.

\section{Authors' contributions}

HS contributed the design of this study, participated in the statistical analysis, and drafted the manuscript. EB carried out the experiment, contributed to the study design, and helped to draft the manuscript. SHK participated in the statistical analysis, contributed to the interpretation of results, and helped to draft the manuscript. All authors read and approved the final manuscript.

\section{Acknowledgements}

This work was supported by research grants from the Catholic University of Daegu in 2014.

\section{Author details}

'Department of Physical therapy, Catholic University of Daegu, 13-13 Hayang-ro, Hayang-eup, Gyeongsan 712-702, Korea. ${ }^{2}$ School of Physical Therapy \& Rehabilitation Sciences, University of South Florida, 12901 Bruce B. Downs Blvd., MDC 77, Tampa, FL 33612, USA.

Received: 30 September 2014 Accepted: 27 March 2015 Published online: 24 April 2015

\section{References}

1. Bax MC, Flodmark O, Tydeman C. Definition and classification of cerebral palsy. From syndrome toward disease. Dev Med Child Neurol Suppl. 2007:109:39-41.

2. Balemans AC, Van Wely L, De Heer SJ, Van den Brink J, De Koning JJ, Becher $J G$, et al. Maximal aerobic and anaerobic exercise responses in children with cerebral palsy. Med Sci Sports Exerc. 2013;45:561-8.
3. McCarthy ML, Silberstein CE, Atkins EA, Harryman SE, Sponseller PD, Hadley-Miller NA. Comparing reliability and validity of pediatric instruments for measuring health and well-being of children with spastic cerebral palsy. Dev Med Child Neurol. 2002;44:468-76.

4. Kwon YH, Lee HY. Differences of respiratory function in children with spastic diplegic and hemiplegic cerebral palsy, compared with normally developed children. J Pediatr Rehabil Med. 2013;6:113-7.

5. Rothman JG. Effects of respiratory exercises on the vital capacity and forced expiratory volume in children with cerebral palsy. Phys Ther. 1978;58:421-5.

6. Hutzler Y, Chacham A, Bergman U, Szeinberg A. Effects of a movement and swimming program on vital capacity and water orientation skills of children with cerebral palsy. Dev Med Child Neurol. 1998;40:176-81.

7. Maltais D, Bar-Or O, Pierrynowski M, Galea V. Repeated treadmill walks affect physiologic responses in children with cerebral palsy. Med Sci Sports Exerc. 2003;35:1653-61.

8. Nsenga AL, Shephard RJ, Ahmaidi S. Aerobic training in children with cerebral palsy. Int J Sports Med. 2013;34:533-7.

9. McPherson JJ, Schild R, Spaulding SJ, Barsamian P, Transon C, White SC. Analysis of upper extremity movement in four sitting positions: a comparison of persons with and without cerebral palsy. Am J Occup Ther. 1991:45:123-9

10. Nwaobi OM, Brubaker CE, Cusick B, Sussman MD. Electromyographic investigation of extensor activity in cerebral-palsied children in different seating positions. Dev Med Child Neurol. 1983;25:175-83.

11. Nwaobi OM, Hobson DA, Taylor SJ. Mechanical and anatomic hip flexion angles on seating children with cerebral palsy. Arch Phys Med Rehabil. 1988:69:265-7.

12. Nwaobi OM, Smith PD. Effect of adaptive seating on pulmonary function of children with cerebral palsy. Dev Med Child Neurol. 1986;28:351-4.

13. Seeger BR, Caudrey DJ, O'Mara NA. Hand function in cerebral palsy: the effect of hip-flexion angle. Dev Med Child Neurol. 1984;26:601-6.

14. McNamara L, Casey J. Seat inclinations affect the function of children with cerebral palsy: a review of the effect of different seat inclines. Disabil Rehabil Assist Technol. 2007;2:309-18.

15. Stavness $C$. The effect of positioning for children with cerebral palsy on upper-extremity function: a review of the evidence. Phys Occup Ther Pediatr. 2006;26:39-53.

16. Cherng RJ, Lin HC, Ju YH, Ho CS. Effect of seat surface inclination on postural stability and forward reaching efficiency in children with spastic cerebral palsy. Res Dev Disabil. 2009;30:1420-7.

17. Redstone $F$. The effects of seating position on the respiratory patterns of preschoolers with cerebral palsy. Int J Rehabil Res. 2004;27:283-8.

18. Ryan SE. An overview of systematic reviews of adaptive seating interventions for children with cerebral palsy: where do we go from here? Disabil Rehabil Assist Technol. 2012;7:104-11.

19. Palisano R, Rosenbaum P, Walter S, Russell D, Wood E, Galuppi B. Development and reliability of a system to classify gross motor function in children with cerebral palsy. Dev Med Child Neurol. 1997;39:214-23.

20. Hadders-Algra M, van der Heide JC, Fock JM, Stremmelaar E, van Eykern LA, Otten B. Effect of seat surface inclination on postural control during reaching in preterm children with cerebral palsy. Phys Ther. 2007:87:861-71.

21. Beukelman DR, Mirenda P. Augmentative \& alternative communication: supporting children \& adults with complex communication needs. 3rd ed. Baltimore, MD: Paul H. Brookes Publishing Company; 2005.

22. Toder DS. Respiratory problems in the adolescent with developmental delay. Adolesc Med. 2000;11:617-31.

23. Hixon TJ, Putnam AH, Sharp JT. Speech production with flaccid paralysis of the rib cage, diaphragm, and abdomen. J Speech Hear Disord. 1983;48:315-27.

24. Song JY. The changes of respiratory functions following postures in cerebral palsy: spastic diplegia. J Kor Soc Phys Ther. 2004;16:115-28.

25. Ryan SE, Campbell KA, Rigby PJ, Fishbein-Germon B, Hubley D, Chan B. The impact of adaptive seating devices on the lives of young children with cerebral palsy and their families. Arch Phys Med Rehabil. 2009;90:27-33.

26. Costigan FA, Light J. Functional seating for school-age children with cerebral palsy: an evidence-based tutorial. Lang Speech Hear Serv Sch. 2011:42:223-36.

27. Winkworth AL, Davis PJ, Adams RD, Ellis E. Breathing patterns during spontaneous speech. J Speech Hear Res. 1995;38:124-44.

28. Shin HK, Kim HS, Lee OB. The effect of seat surface inclination on respiratory function and speech production in sitting. J Kor Soc Phys Ther. 2012;24:29-34. 
29. Miedaner J. The effects of sitting positions on trunk extension for children with motor impairment. Pediatr Phys Ther. 1990;2:11-4.

30. Sochaniwskyj A, Koheil R, Bablich K, Milner M, Lotto W. Dynamic monitoring of sitting posture for children with spastic cerebral palsy. Clin Biomech. $1991 ; 6: 161-7$.

31. Reid DT, Sochaniwskyj A. Effects of anterior-tipped seating on respiratory function of normal children and children with cerebral palsy. Int J Rehabil Res. 1991;14:203-12.

32. Dault MC, Yardley L, Frank JS. Does articulation contribute to modifications of postural control during dual-task paradigms? Brain Res Cogn Brain Res. 2003;16:434-40.

33. Workinger MS. Cerebral palsy resource guide for speech-language pathologists. 1st ed. Thomson Delmar Learning: Clifton Park, NY; 2005.

34. Chiara T, Martin D, Sapienza C. Expiratory muscle strength training: speech production outcomes in patients with multiple sclerosis. Neurorehabil Neural Repair. 2007;21:239-49.

\section{Submit your next manuscript to BioMed Central and take full advantage of:}

- Convenient online submission

- Thorough peer review

- No space constraints or color figure charges

- Immediate publication on acceptance

- Inclusion in PubMed, CAS, Scopus and Google Scholar

- Research which is freely available for redistribution 